\title{
Empreendedorismo internacional e Effectuation: O caso do Café Yaguara Ecológico
}

\author{
Paula Porto ${ }^{1 \mathrm{~A}}$ e Renato Cotta de Mello ${ }^{\mathrm{B}}$ \\ ${ }^{A}$ Pontifícia Universidade Católica do Rio de Janeiro - PUC/RJ, Rio de Janeiro, RJ, Brasil. \\ ${ }^{B}$ Universidade Federal do Rio de Janeiro - UFRJ/RJ, Rio de Janeiro, RJ, Brasil.
}

\begin{tabular}{l}
\hline DETALHES DO ARTÍGO \\
\hline Histórico do Artigo: \\
Recebido em 09 de Dezembro de 2014 \\
Aceito em 01 de Julho de 2015 \\
Disponível online em 19 de Dezembro de 2015 \\
Sistema de Revisão “Double Blind Review” \\
Editor Científico \\
Felipe Mendes Borini
\end{tabular}

\section{Palavras-chaves:}

Empreendedorismo Internacional

Effectuation

Café

Brasil

\begin{abstract}
RESUMO
O objetivo deste estudo é investigar o papel do empreendedor e as características do processo de internacionalização de uma pequena empresa brasileira produtora de café, Yaguara Ecológico, à luz de diferentes abordagens teóricas. Foi realizada uma revisão da literatura com atenção especial às teorias de Empreendedorismo Internacional e Effectuation. O presente trabalho trata do fenômeno da International New Venture (OVIATT; McDOUGALL, 1994) e, com intuito de compreender a relevância dos empreendedores no processo de internacionalização da empresa, foi eleita a teoria Effectuation que oferece alternativas para descrever como estes pensam e se comportam ao iniciar um novo empreendimento (PERRY et al., 2012). O método para a pesquisa foi o estudo de caso único e entrevistas em profundidade foram realizadas com gestores da empresa. Os resultados sugerem que as teorias ofereceram explicações para os movimentos de internacionalização da empresa, entretanto, algumas características dessa trajetória não aderiram às proposições teóricas.
\end{abstract}

(c) 2015 Internext | ESPM. Todos os direitos reservados!

\section{Introdução}

O presente trabalho tem por objetivo investigar o papel do empreendedor e as características do processo de internacionalização de uma pequena empresa brasileira, utilizando as proposições teóricas de empreendedorismo internacional e a teoria Effectuation. Nesse sentido foi eleita a empresa Yaguara Ecológico, produtora de café orgânico, localizada na cidade de Taquaritinga do Norte, no sertão do estado de Pernambuco, que exporta grande parte de sua produção para o mercado japonês.

De acordo com o Ministério da Agricultura, em 2012, o setor cafeeiro foi responsável por cerca de $7 \%$ das exportações agrícolas brasileiras, o que representou um faturamento anual em torno de 6,5 bilhões de reais (Informe Café, 2013). Por pertencer ao setor cafeeiro, a empresa escolhida confere relevância à pesquisa, uma vez que o café é a commodity mais comercializada no mundo, sendo o Brasil líder do setor desde 1840, tendo produzido 48.1 milhões de sacas de 60kgs em 2010, o que correspondeu a $36 \%$ da produção mundial (GONZALEZ-PEREZ; GUTIERREZ-VIANA, 2012).

Sob a perspectiva teórica, de acordo com Martignago e Alperstedt (2011), a área de pesquisa em gestão internacional no Brasil se encontra em formação e, portanto, avanços podem ser feitos nessa área do saber. Kiss et. al. (2013) salientam que, no campo do empreendedorismo internacional, poucos estudos foram realizados no Brasil. Essas constatações guardam relação com o fato de que os estudos sobre Empreendedorismo Internacional são recentes também no âmbito global, tendo suas origens em meados da década de 1990 e compreendem uma multidisciplinaridade de pesquisas que buscam salientar as diferentes características na internacionalização das pequenas

\footnotetext{
${ }^{1}$ Contato do autor: Email: paulappontes@gmail.com
} 
empresas que, com pouco tempo de existência, ingressam no mercado internacional (McDOUGALL et al., 2003). Além disso, de acordo com Mitgwe (2006), os estudos sobre Empreendedorismo Internacional constituem o estado da arte das pesquisas sobre internacionalização de empresas, sendo um rico campo para desenvolvimento de pesquisas e com escopo ainda indefinido (OVIATT; McDOUGALL, 2005).

A escolha da teoria Effectuation também confere relevância teórica a este estudo uma vez que questiona a lógica do desenvolvimento de novos empreendimentos ao suscitar as prerrogativas do comportamento e do pensamento dos empreendedores, lançando no campo de estudos sobre empreendedorismo uma mudança paradigmática que inverte os aspectos causais da racionalidade (READ; SARASVATHY, 2005; PERRY et al., 2012). Ademais, poucos estudos utilizaram a perspectiva da teoria Effectuation na análise do processo de internacionalização de empresas (COVIELLO; JONES, 2004; ANDERSON, 2011; GALKINA; CHETTY, 2011; JONES et al., 2011).

Some-se a isso a constatação de que a grande maioria dos estudos sobre empreendedorismo internacional e Effectuation examina o poder explanatório dessas teorias tendo como objeto, principalmente, empresas do hemisfério norte que atuam no setor tecnologia da informação (GALKINA; CHETTY, 2012; PERRY et al., 2012; COVIELLO et al., 1998, RIALP et al., 2005). Assim, o presente trabalho busca contribuir para o campo de estudos sobre essas teorias, utilizando como referência uma pequena empresa brasileira que atua no setor de agronegócios.

Excetuando-se a parte introdutória e as considerações finais, o presente artigo está dividido em quatro seções. Na primeira seção encontra-se o referencial teórico onde as teorias de Empreendedorismo Internacional e Effectuation são apresentadas. Na segunda seção, descreve-se o método de pesquisa utilizado. Na terceira seção, o caso Yaguara Ecológico é apresentado. Na quarta seção são expostas as convergências e divergências entre o caso estudado e o referencial teórico utilizado.

\section{Referencial Teórico \\ 2.1 Empreendedorismo Internacional}

De acordo com (Rialp et al. 2005 HILAL; HEMAIS, 2003, KEUPP \& GAUSMANN, 2009) o campo de empreendedorismo internacional ganhou relevância a partir dos anos 1990 quando alguns trabalhos (McDOUGALL, 1989; OVIATT; McDOUGALL, 1994, McDOUGALL et al., 1994) começaram a encontrar resultados de pesquisas empíricas que não condiziam com o modelo tradicional de internacionalização desenvolvido por pesquisadores da Escola de Uppsala (JOHANSON; WIEDERSHEIM-PAUL, 1975; JOHANSON; VAHLNE, 1977). Os resultados demonstravam que algumas empresas se internacionalizavam de maneira mais rápida e, não necessariamente, em estágios sequenciais (AUTIO, 2005).

Além disso, de acordo com Zahra e George (2002), as pequenas e médias empresas também ganharam um papel importante na economia mundial e, o entendimento sobre as motivações, padrões e caminhos percorridos por estas no âmbito internacional, também foram motivos suficientes para diversos pesquisadores (ROCHA et al. 2003; DIB, 2008; CASILLAS; ACEDO, 2013) buscarem aprofundar o conhecimento sobre esse tipo de empresa.

O primeiro modelo que buscou explicar o fenômeno do empreendedorismo internacional foi elaborado por Oviatt e McDougall (1994). Esse modelo é composto por quatro elementos que os autores julgaram necessários e suficientes para formação de uma INV - International New Venture. Eles podem ser descritos da seguinte forma: Elemento 1: Internalização de Algumas Transações: a empresa opta por reduzir custos ao executar operações ao invés de recorrer ao mercado. Elemento 2: Estruturas de Governança Alternativas: estruturas hibridas, como as alianças estratégicas, que funcionam como alternativas plausíveis para o controle interno e o controle de mercado sobre os recursos. Elemento 3: Vantagem da Localização Estrangeira: organizações são internacionais porque encontram vantagens ao transferir ou obter recursos (matéria prima, conhecimento, produtos) além fronteiras, de modo a combiná-los com recursos imóveis ou oportunidades. Elemento 4: Recursos Únicos: Os três primeiros elementos definem as condições necessárias para a existência das INV's. Entretanto, essas condições não são suficientes para obter uma vantagem competitiva sustentável, sendo necessário, então, que a firma disponha de recursos 
únicos -VRIO - valor, raro, inimitável e insubstituível (BARNEY, 1991).

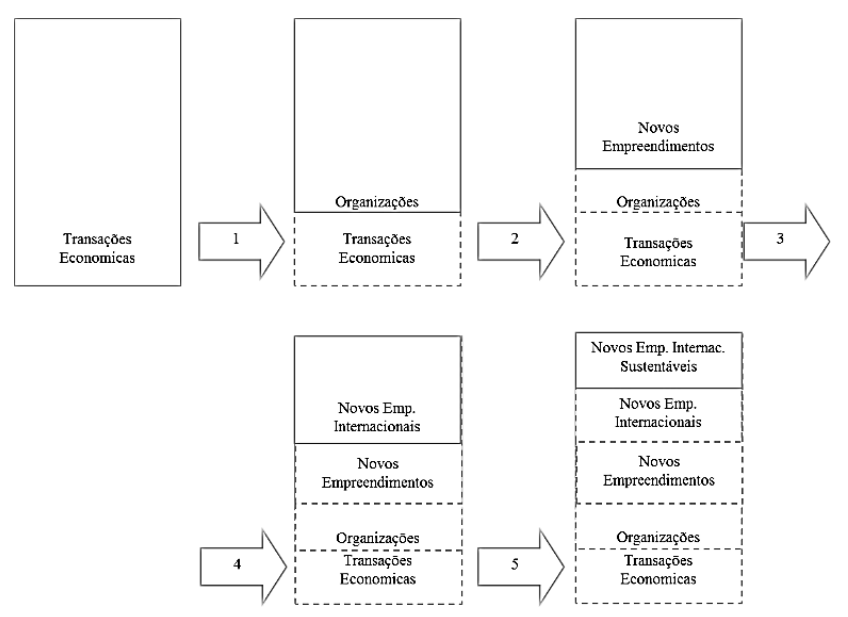

Figura 1: Modelo de INV

Fonte: Adaptado de Oviatt e McDougall (1997, p. 54).

Além do modelo, um aspecto evidenciado pela teoria de Empreendedorismo Internacional diz respeito à relevância da figura do empreendedor para entender a complexidade do fenômeno da internacionalização das empresas (MELLO, 2009, KEUPP; GAUSSMAN, 2009). Os trabalhos de McDougall, 1989, Oviatt e McDougall, 1994, Oviatt et al., 1994 evidenciam a figura do empreendedor no processo de internacionalização e sugerem que o mesmo tem o poder de alterar as circunstâncias.

Andersson (2000) utiliza a definição de Schumpeter (1934), que entende o empreendedor como função, ou seja, aquele que tem habilidade de ver novas combinações, convencer outros a investirem no negócio e agir de acordo com um ponto de vista ao invés de ficar preso a cálculos racionais. Assim, Andersson (2000) cria um modelo no qual relaciona os diferentes níveis de combinações macro (por exemplo, distância psíquica), meso (por exemplo, consumidores, competidores e networks) e da empresa (por exemplo, estrutura organizacional, produtos, cultura e aprendizagem) - com o conceito de processo estratégico e de internacionalização de empresas.

Através desse modelo, o autor sugere que o empreendedor exerce influência sobre a cultura organizacional, podendo atuar de forma divergente às práticas tradicionais e tem capacidade para acelerar a internacionalização do negócio. Por fim, o autor classifica três tipos de empreendedores: o técnico (com capacidade para gerar novos produtos mesmo que ainda não haja demanda); o estrutural (que atua em setores maduros e age no sentido de formar estruturas alternativas de governança corporativa) e o de mercado (capaz de criar canais para alcançar clientes).

Simões e Dominguinhos (2001) explicam que além das mudanças no contexto, o empreendedor surge como fator decisivo para a explicação do fenômeno de empreendedorismo internacional por ter mais conhecimento científico, deter maiores habilidades em marketing, em relacionamentos e em visão de negócios. Pelogio et al. (2013), por sua vez, destacam que o empreendedor desempenha uma função social de identificar as oportunidades, sendo a prática de empreender um ato criativo que ocorre em circunstâncias de riscos e incertezas.

\subsection{Teoria Effectuation}

De acordo com Perry et al. (2012), a teoria Effectuation apresenta uma mudança paradigmática nos estudos sobre empreendedorismo. Se, por um lado, os estudos, tradicionalmente, elegiam como base teórica o modelo racional de decisão, baseado na economia neo-clássica, por outro, a teoria Effectuation inverte o modelo racional de decisão ao modificar e apresentar outro direcionamento em relação aos princípios fundamentais, de espaço, solução e lógica do processo tradicional referido como causal (READ; SARASVATHY, 2005).

Sarasvathy (2001a) percebeu que havia um padrão no modo como empreendedores criam mercados e empresas. Esse padrão constituía-se de características que eram diferentes da lógica causal/preditiva. Ao conceber a teoria Effectuation a autora pensou, criticamente, sobre a existência de um universo pré-concebido e de mercados existentes. Assim, propôs uma alternativa filosófica na qual a ação do ser humano transforma a realidade em novas possibilidades (RONDANI et al., 2012).

De acordo com Sarasvathy e Venkataraman (2001), a razão causal e a lógica de previsão têm sido as bases para responder a perguntas acerca do comportamento, diferenciação, escopo e desempenho das empresas. Entretanto, a perspectiva de ação criativa baseada na razão effectual e na lógica de controle pode fornecer explicações para essas perguntas, o que significa que, o processo empreendedor segue um percurso criativo e, não somente, de descoberta e alocação de recursos. 


\section{Effectuation}

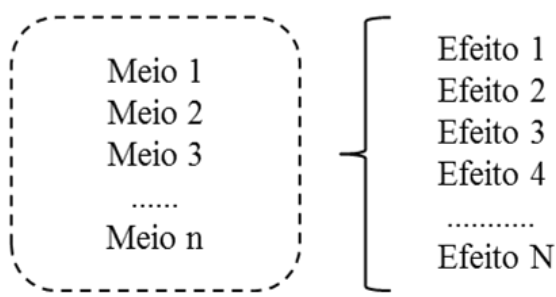

Figura 2: Lógica Effectual versus Lógica Causal

Fonte: Adaptado de Sarasvathy, 2001b (p.2).

Assim, enquanto a criatividade na perspectiva da razão causal consiste em gerar meios alternativos para o alcance de objetivos predeterminados, a criatividade na lógica effectual envolve a geração de possíveis objetivos, dadas as limitações dos meios e as dificuldades do ambiente dinâmico e interativo (SARASVATHY; VENKATARAMAN, 2001). Portanto, Sarasvathy (2001a p. 245; 2001b) define causalidade como: "processo que assume um efeito particular como dado e foca em selecionar entre meios para criar um resultado." Enquanto Effectuation é definido pela autora como: "processo que assume um conjunto de meios como dado e foca em selecionar entre possiveis resultados que podem ser criados com esse dado conjunto de meios."

De acordo com Wiltbank et al. (2006) após acessarem os "meios", os empreendedores observam quais são as direções possíveis e, em seguida, buscam pessoas com intuito de obter recursos para dar prosseguimento à ação escolhida. Essas pessoas podem ser possíveis stakeholders. Assim que encontram pessoas que queiram participar da ação escolhida (essa ação, entretanto, pode ser

\section{Causalidade}

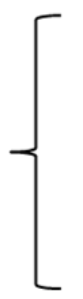

algo vago ou concreto, mas aberto a mudanças), eles se movimentam com objetivo de firmar compromissos com esses parceiros. Cada parceiro envolvido compromete-se em contribuir na construção da visão de futuro e com as estratégias particulares que serão adotadas a fim de concretizar essa visão.

A teoria Effectuation sugere que o tomador de decisão não fica amarrado à previsibilidade do cenário, mas é o agente transformador que proverá as condições necessárias para o contexto lhe seja favorável. Para ilustrar esse pensamento, a autora sugere o exemplo do jogo da urna, em que o objetivo é adivinhar o numero de bolas vermelhas e o prêmio é no valor de \$50. Na visão Effectuation o decisor não ficará preso às estimativas, ele simplesmente encontrará uma maneira de encher a urna de bolas vermelhas e convencerá os parceiros a encherem a urna com bolas vermelhas e se, por acaso, só existirem bolas verdes disponíveis para serem colocadas na urna, ele mudará as regras do jogo.

Nesse sentido, duas frases escritas por Sarasvathy (2001a, p.251) resumem a maneira como ocorre o

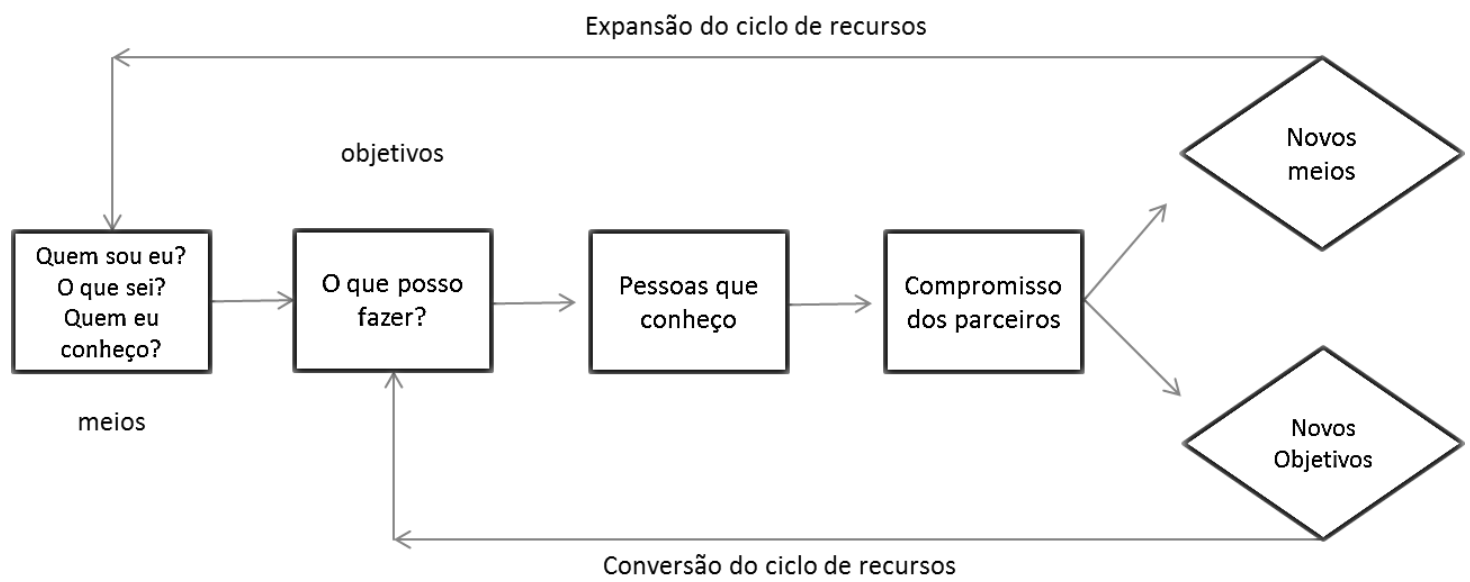

Figura 3: Ciclo de ação do Empreendedor

Fonte: Adaptado de Wiltbank et al. (2006; pg. 992). 
pensamento de um tomador de decisão que segue a lógica causal: "À medida que podemos prever o futuro, podemos controlá-lo", daqueles que seguem a lógica Effectuation: "À medida que controlamos o futuro, não precisamos prevê-lo". Wiltbank et al., 2006 classifica a lógica Effectuation, em termos de controle e previsibilidade, como transformativa porque apresenta alto nível de controle sem chamar de previsibilidade.

Sarasvathy (2003) então, sugere a existência de uma lógica particular de controle que distingue-se da proposição causal em razão de três princípios:

- Perdas aceitáveis ao invés de retornos esperados: a lógica causal visa o maior retorno utilizando estratégias ótimas, enquanto, na lógica Effectuation, o valor de perda é predeterminado e verifica-se quais estratégias são possíveis;

- Parceiros ao invés de competição: na teoria causal, utilizam-se as ferramentas estratégicas (por exemplo, de Michael Porter) para uma análise competitiva. Na teoria Effectuation, constrói-se o compromisso com os stakeholders para que sejam minimizadas as incertezas, ao mesmo tempo em que são criadas barreiras de entrada;

- Alavancar contingências ao invés de evitá-las: se existe um conhecimento prévio sobre uma inovação, a teoria causal pode ser melhor aplicada. Entretanto, se novas possibilidades podem ocorrer ao longo do tempo, a teoria Effectuation seria a melhor opção.

Por fim, Sarasvathy (2001a; 2001b) coloca que o processo da lógica Effectuation envolve o desenho dos possíveis objetivos e não apenas a escolha desses, por conseguinte, a razão causal depende do resultado final, enquanto a effectual depende diretamente do ator (SARASVATHY; VENKATARAMAN, 2000).

\subsection{Relacionando as Teorias}

Para investigar as características do processo de internacionalização da firma objeto deste estudo, são utilizadas as teorias de Empreendedorismo Internacional e Effectuation.

No que diz respeito ao fenômeno do Empreendedorismo Internacional são avaliados os subsets essenciais propostos por Oviatt e McDougall, 1994 de modo a confirmar se esta é de fato uma INV que contém os elementos necessários enumerados pelos autores, bem como se o nível de comprometimento da sua cadeia de valor é compatível com o seu processo de internacionalização.

No que tange ao papel do empreendedor e a lógica de seu processo de tomada de decisões será utilizada a teoria Effectuation, na medida em que diversos autores como McDougall (1989), Oviatt e McDougall, (1994), Oviatt et al. (1994) e Andersson (2000) evidenciam a relevância do papel do empreendedor para o ingresso da firma em mercados no exterior.

Ademais, a teoria Effectuation é interessante porque oferece alternativas para descrever como o empreendedor pensa e se comporta ao iniciar um novo empreendimento (PERRY et al., 2012), ou seja, pode ser uma teoria válida para descrever alguns aspectos do processo que origina um empreendimento, especialmente aqueles que pretendem se internacionalizar desde sua origem. Por sua vez, outros autores (COVIELLO E JONES, 2004;

\section{Tabela 1}

Resumo das diferenças entre a perspectiva causal e a perspectiva effectual

\begin{tabular}{|c|c|c|}
\hline Tópico & Perspectiva causal & Perspectiva effectual \\
\hline Visão do futuro & $\begin{array}{l}\text { Logica que prevê o futuro } \\
\text { como continuação do passado }\end{array}$ & Futuro é construído por agentes \\
\hline Base de ação & Orientado pelos objetivos & Orientado pelos "meios" \\
\hline Predisposição a risco e recursos & Expectativa de retorno & Riscos aceitáveis \\
\hline Atitude frente aos outsiders & Competição & Parcerias \\
\hline $\begin{array}{c}\text { Atitudes frente a } \\
\text { contingências inesperadas }\end{array}$ & $\begin{array}{l}\text { Contingências são obstáculos } \\
\text { que devem ser evitados }\end{array}$ & $\begin{array}{l}\text { Contingências são vistas como } \\
\text { oportunidades para criação }\end{array}$ \\
\hline
\end{tabular}

Fonte: Adaptado de Dew et al. (2009, p.290) 
JONES et al., 2011) verificaram que a teoria Effectuation se insere como conceito relevante no campo de negócios internacionais especialmente no que diz respeito à tomada de decisão no contexto de internacionalização e de empreendedorismo.

\section{Método de Pesquisa}

\subsection{Estudo de Caso}

As pesquisas sobre empreendedorismo internacional, assim como os estudos que investigam o poder explanatório da teoria Effectuation, estão em seus estágios iniciais (ANDERSSON, 2011, GALKINA; CHETTY, 2011) e se propõem a olhar diferentes fenômenos sob nova ótica. Esses fenômenos dialogam entre si pela figura do empreendedor que é agente no processo de criação do empreendimento e de sua internacionalização (KEUPP; GAUSSMAN, 2009; JONES, et al. 2011, ANDERSSON, 2011). Assim, de acordo com Eisenhardt (1989) o estudo de caso é apropriado como método a ser aplicado em circunstancias onde a área de pesquisa está em estágio de desenvolvimento inicial ou se propõe a ser uma nova perspectiva para o campo de investigação.

De acordo com Ghauri (2004) a seleção do caso é de extrema relevância e deve combinar teoria com pragmatismo, ou seja, deve atender às questões de pesquisa e estar disponível para pesquisa. Nesse sentido, a empresa Yaguara Ecológico atendeu aos dois critérios uma vez que os gestores se disponibilizaram a participar das entrevistas e as características do processo de internacionalização sugerem aspectos particulares, dado tratar-se de uma pequena empresa brasileira do setor de agronegócios e que exporta grande parte de sua produção diretamente para o mercado japonês.

Feita a escolha do estudo de caso, Yin (2005) coloca a importância da escolha entre um método de casos múltiplos ou caso único. De acordo com Ghauri (2004) a seleção de um caso único é adequado para estudos exploratórios que servem de primeiro estágio para futuros estudos. De acordo com Kiss et al. (2012), poucos estudos sobre empreendedorismo internacional foram feitos no Brasil e, portanto, há possibilidade de geração de insights sobre um fenômeno contemporâneo (VARIS et al., 2005). Ademais, de acordo com Perry et al. (2012), a opção pelo estudo de caso único tem sido a opção mais comumente utilizada quando a teoria Effectuation é estudada, destacando-se que, segundo Birkinshaw et al. (2011) o método de estudo de caso desempenha um importante papel nos estudos de negócios internacionais porque é um meio de análise alternativo sobre o papel do indivíduo nas organizações e pode gerar compreensões profundas sobre o contexto fornecendo respostas a perguntas de como, quando e por que.

Para realizar a coleta de dados, em dezembro de 2013, foram realizadas entrevistas presenciais na empresa, localizada em Taquaritinga do Norte, interior do estado de Pernambuco, onde trabalham dois gestores da empresa, sendo que a sociedade é composta por seis cotistas pertencentes à mesma família. Durante a estadia do pesquisador no local foram realizadas três entrevistas com os dois residentes, com tempo médio de noventa minutos de duração cada uma. Em seguida, foram realizadas mais duas entrevistas, também com tempo médio de noventa minutos de duração, via Skype, com outros

Tabela 2

Categorias de Análise do Estudo

\begin{tabular}{lll}
\hline \multicolumn{1}{c}{ Dimensão } & \multicolumn{1}{c}{ Principais Variáveis } & \multicolumn{1}{c}{ Aporte Teórico } \\
\hline $\begin{array}{c}\text { Empreendedorismo } \\
\text { Internacional }\end{array}$ & - Processo de criação da empresa; & BARNEY, 1991; OVIATT; McDOUGALL, 1994; \\
& - Processo de busca pelo mercado internacional; & MADSEN, T. K.; SERVAIS, P., 1997; ANDERSSON, S., \\
& - Escolha do mercado no exterior; & 2000; RIALP, A., RIALP, J. et.al. KNIGHT, G. A., \\
& efetivação do 1o negócio no exterior; & M.V., COVIELLO, N. e TANG, Y.K., 2011; KISS, A. N., \\
& - Evolução do processo de internacionalização; & DANIS, W. M. and CAVUSGIL, S. T., 2012. \\
& - Alianças e parcerias. & \\
\hline Effectuation & - Perfil demográfico do executivo principal; & SARASVATHY, S., 2001a; WILTBANK, R., DEW, N. \\
& - Visão de negócio da empresa; & READ, S. e SARASVATHY, S., 2006; DEW et.al., \\
& - Características/lógica das mais importantes & 2009; GALKINA, T.; CHETTY, S., 2011.; PERRY, J.P.,, \\
& tomadas de decisão; & CHANDLER, G. N. e MARKOVA, G., 2012; RONDANI, \\
& - Processo de busca por parcerias nacionais e & B., ANDREASSI, T., and BERNARDES, R.C.,2013. \\
& internacionais; & \\
& - Visão de futuro do gestor. & \\
\hline
\end{tabular}

Fonte: Desenvolvido pelos autores. 
dois gestores da Yaguara Ecológico, que residem nos Estados Unidos. As entrevistas foram realizadas com base no roteiro de entrevistas semiestruturado, que foi elaborado tendo como base as dimensões e variáveis que seriam investigadas, conforme exposto na Tabela 2.

De acordo com Perren e Ram (2004), esta pesquisa classifica-se como estudo de caso, exploratória, com perspectiva objetiva da narrativa empreendedora, sendo a unidade de análise a empresa.

Adicionalmente às entrevistas, um total de 23 documentos foi coletado, incluindo documentos internos da empresa, artigos em revistas e jornais, além de informações coletadas na Internet. A utilização de diferentes fontes permitiu a triangulação de dados, assegurando a validade e credibilidade dos mesmos (GIBBERT et al., 2008). O material coletado foi analisado através da quebra (corte) do mesmo em trechos que foram alocados nas categorias de análise levantadas a partir da revisão da literatura (DOLAN; AYLAND, 2001).

\section{O Caso Yaguara Ecológico}

\subsection{Internacionalização do Café produzido na Várzea da Onça}

De propriedade da família Peebles, a fazenda Várzea da Onça, onde é produzido o Café Yaguara, localizase na cidade de Taquaritinga do Norte, região do agreste setentrional de Pernambuco. Nesta região a vegetação é predominantemente do tipo Mata Atlântica e já foi um polo produtor café do tipo arábica.

Na região de Taquaritinga (do Norte), a cultura cafeeira existe desde antes de eu nascer. Existem pés de café com mais de 100 anos de idade. É possivel ver a idade devido à espessura do ramo (...) quanto mais grosso, mais velho o pé de café. Naquele tempo plantava-se avulso e não enfileirado. Colhia-se somente o grão cereja, catado à mão. (Informante III).

A espécie arábica (Coffea arabica L.) é de qualidade superior (PROCAFÉ, 2013). Entretanto, a partir da década de 1990 a crescente oferta de trabalho manufatureiro em Santa Cruz do Capibaribe, cidade vizinha à Taquaritinga do Norte, esvaziou o interesse dos agricultores da região pela cultura cafeeira.

Os familiares que herdavam as propriedades dos pais não queriam mais saber de plantar café. O interesse era em trabalhar nas indústrias porque o retorno financeiro é mais rápido. (Informante IV)
Nesse mesmo período, a economia cafeeira nacional passava por uma crise advinda da perda de valor das commodities no mercado mundial (LEÃO, 2010). Com o setor desregulado, novos padrões de consumo constituíram um cenário que conduziu os produtores de café a considerarem a qualidade e a sustentabilidade produtiva do café como diferenciais, possibilitando o surgimento do nicho de cafés especiais. Entretanto, o mercado ainda era incipiente e despertava timidamente (LEÃO, 2010).

Apesar do cenário constituir-se pouco favorável, a família Peebles sabia que o café natural da região de Taquaritinga do Norte era peculiar e poderia diferenciar-se das commodities. Além das características inerentes ao café, a família acreditava que poderia imprimir qualidade no produto ao manejá-lo de forma sustentável e dentro dos critérios do cultivo orgânico.

A ideia de cultivar o café arábica à sombra dentro da floresta começou a ser colocada em prática e no inicio da década de 1990, apesar da redução alfandegária que abriu espaço para a importação de cafés especiais, ainda não havia mercado doméstico estabelecido que sustentasse a produção. A família estava diante de um dilema: abrir mão da qualidade do café e competir no mercado de cafés populares ou encontrar um mercado consumidor que demande o produto que tinham em mãos.

\begin{abstract}
Naquela época não tinha mercado no Brasil. Até a poucos anos atrás, tudo o que era de bom (em termos de café) era exportado e ficava o refugo no país. Em todo lugar tinha esse conceito de você exportar o melhor, e deixar o ruim ficar. O consumidor brasileiro agora é que está despertando para a qualidade do produto. (Informante I).
\end{abstract}

Então para deslanchar as suas atividades comerciais, em 2000 Tatiana Peebles e James Mclaughlin participaram de uma feira de café nos Estados Unidos com vista a comercialização do café no exterior, uma vez que não existia consistência no mercado nacional para cafés especiais. Essa feira era promovida pela Specialty Coffee Association of America (SCAA) e, durante o evento, os dois tiveram a oportunidade de conversar com um grupo de japoneses da empresa Ueshima Coffee Company (UCC), com escritório em São Paulo, quando explicaram sobre o tipo de café que vinha sendo cultivado na fazenda do sertão pernambucano.

Tatiana e James descreveram as particularidades do café para o grupo de japoneses. Primeiro, eles indicaram que a espécie de café oriunda da fazenda 


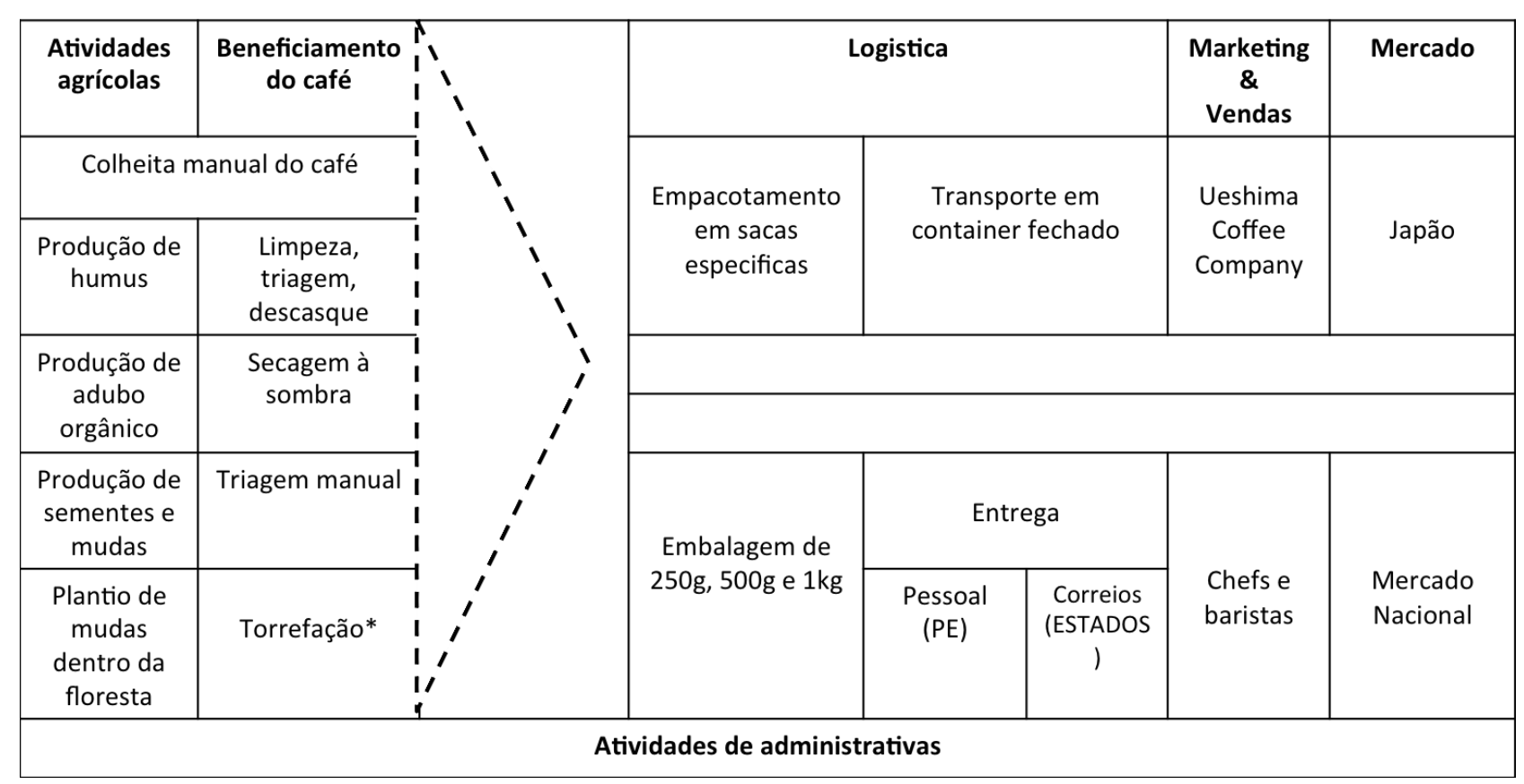

Figura 4: Cadeia de Valor da Yaguara Ecológico. * A torrefação é realizada nos grãos destinado ao mercado nacional. Fonte: Elaborado pelos autores

era do tipo arábica, típica de Mata Atlântica, e que os pés eram cultivados à sombra. Depois expuseram para os japoneses que, aliado à singularidade da espécie, o manejo do café era realizado dentro dos princípios da agricultura orgânica, ou seja, não utilizava pesticidas no combate de brocas e pragas da lavoura, e preservava a flora e fauna local, o que significa dizer que não havia desmatamento da floresta nativa para plantar pés de café. Além disso, a equipe de trabalhadores rurais, que realizavam o serviço da lavoura, eram legalizados com seus direitos respeitados perante as leis do país.

Em relação às atividades desenvolvidas, pode-se afirmar que a fazenda preservava um conjunto de práticas tradicionais aliadas à tecnologia. Se por um lado o cultivo e a colheita do café são feitos integralmente de modo manual e fiel aos princípios da agricultura orgânica, o beneficiamento do café conta com uma infraestrutura avançada.

Após a conversa ocorrida na feira, o interesse dos japoneses ficou desperto e, cerca de duas semanas depois, um representante da UCC visitou a fazenda durante dois dias para acompanhar o processo produtivo e averiguar se o café estava sendo produzido de acordo com as especificidades mencionadas por Tatiana e James.
Eles queriam saber se nós estávamos preservando a fauna e a flora, se estávamos cuidando do meio ambiente $e$ se os funcionários estavam sendo tratados com dignidade. É o que eles chamam de macro e microecologia. Existe uma preocupação com a origem alimentar (...) Se você pensar, tudo tem uma história por atrás, tudo (Informante III).

Além da visita ao campo, o grupo de japoneses enviou a uma amostra do café para análise em laboratório e, somente após certificarem-se de que o café era orgânico, as negociações tiveram início. Em 2004, quando foi efetivada a primeira exportação para o Japão, o carregamento foi de apenas 10 sacas de $60 \mathrm{kgs}$ do café tipo $17 / 18$, numeração que equivale aos maiores grãos existentes, considerados de qualidade superior (Guia do Café - International Trade Centre, $2013^{2}$ ). Os grãos enviados ao Japão são do tipo verde in natura, ou seja, não passam pelo processo de torrefação. Esse café verde é vendido e torrado no Japão com o nome de Café Pernambucano nas boutiques de café da UCC. Além disso, o café verde in natura é vendido em leilões realizados pelos japoneses.

A exportação para o Japão exigiu uma série de adaptações por parte da empresa. Para o transporte, o café teve que ser embalado em sacos de estopa virgem e com determinada marcação. Além do saco

\footnotetext{
${ }^{2}$ Tamanhos dos grãos de café. Disponível em http://www.thecoffeeguide.org/coffee-guide/coffeequality/bean-size/. Acesso em fevereiro de 2014
} 
de estopa outra embalagem plástica teve que ser colocada por dentro do saco de estopa. Os baús de armazenamento das sacas deveriam ser fechados, higienizados e nada poderia afetar o cheiro do café. Quando se destina ao mercado doméstico, o transporte do café segue outra orientação, sem tanta rigidez. Nas palavras de um dos empreendedores:

Geralmente, no Brasil, o café vai armazenado no caminhão com uma lona de cobertura. Os japoneses não permitem que nada afete a integridade do produto. Eles querem baú fechado que é muito caro. O baú tem que ser limpo, mas não podemos utilizar nada que afete o cheiro do café. As estopas de juta têm que ser virgens. Então, eles seguem um protocolo rígido de qualidade que para a gente já virou rotina (Informante I)

Em relação aos grãos, a seleção dos mesmos é rigorosa. Os japoneses só aceitam comprar os grãos de tamanho 17/18 e descartam a possibilidade de comprar os demais de tamanho inferior. Por isso quando há grãos suficientes, existe negócio, caso contrário, não há o que fazer.

Eles querem um grão perfeito, parecendo um rosário, um igual ao outro. Então, sobra o que não é perfeito, perfeito (Informante II).

No ano de 2001, a fazenda Várzea da Onça adquiriu a primeira máquina de beneficiamento de café. Essa máquina separa os frutos colhidos em maduros, verdes e defeituosos, e descasca separando a semente da polpa. Inicialmente, a seleção dos grãos era feita de forma manual. Posteriormente a fazenda adquiriu uma máquina que separa os grãos pelo tamanho, de modo a ter mais precisão e agilidade no processo de categorização.

Com a expansão da fazenda e o trabalho do solo, anualmente, a fazenda Várzea da Onça consegue enviar em torno de 60 a 150 sacas (dependendo da safra, disponibilidade do tamanho de grão, e demanda de mercado interno) para a UCC, seu cliente exclusivo em transações internacionais. A parceria com a firma japonesa é relevante para a empresa porque metade do seu faturamento anual é proveniente dessa transação. Tatiana explica que a precificação do café para exportação é feita anualmente logo após a safra. De acordo com

\footnotetext{
${ }^{3}$ Brazilian Specialty Coffee Association of Brazil. Informações sobre o mercado cafeeiro. Disponivel em:

http://bsca.com.br/noticia.php?id=235. Acesso em março de 2014.
}

Brazilian Specialty Coffee Association (BSCA ${ }^{3}$ ) o café verde especial chega a ser comercializado a 6,95 libra-peso, o que equivale a 919,35 dólares pela saca de $60 \mathrm{~kg}$, sendo o café tradicional comercializado na bolsa de Nova York a 200 dólares a saca de $60 \mathrm{~kg}^{4}$.

Em paralelo à comercialização com os japoneses, que se estende até os dias atuais, entre os anos de 2001 e 2007, o café da fazenda também foi exportado para os Estados Unidos. Os grãos de numeração inferior, aqueles que não eram comercializados na UCC eram enviados para Miami onde passavam pelo processo de torrefação e, em seguida, eram vendidos em pequenos comércios locais. Nessa época, o café da fazenda, comercializado nos Estados Unidos, tinha a marca "Café Sombra", e a família alugou um galpão na região de Miami, onde instalou máquinas de torrefação de café.

Vários motivos levaram a família a exportar os demais grãos para os Estados Unidos. O primeiro motivo foi o fato de que Tatiana ainda morava por lá e, na perspectiva deles, no Brasil não havia mercado para comercializar um café especial:

\begin{abstract}
Naquela época não tinha mercado no Brasil. Até poucos anos atrás, tudo o que era de bom era exportado e ficava o refugo no país. Em todo lugar tinha esse conceito de você exportar o melhor, e deixar o ruim ficar. O consumidor brasileiro agora é que está despertando para a qualidade do produto. (Informante III).
\end{abstract}

Entretanto, o trabalho de torrefação do café nos Estados Unidos não deu certo. Se por um lado, o mercado norte americano oferecia janelas para comercialização do "Café Sombra", por outro, a mão de obra necessária para o trabalho era inadequada e o comércio varejista local exigia altos valores para comercializar o produto nas gôndolas o que tornou a operacionalização inviável e a atividade foi encerrada em 2007:

Não deu certo porque a mão de obra em Miami era muito difícil, ninguém queria aprender a fazer do modo como entendíamos ser o correto. Além disso, os custos de produção nos Estados Unidos eram muito altos. 0 negócio ficou difícil e complicado. Então resolvemos não enviar mais o café remanescente para os Estados Unidos. Preferimos vender o café no Brasil (Informante II).

\footnotetext{
${ }^{4}$ Revista Cafeicultura. Cotação do dia do café na bolsa de Nova York. Disponível em: http://www.revistacafeicultura.com.br/index.php?tipo=ler\&ma $\mathrm{t}=52769$ \&cotacao-do-cafe----operacoes-no-mercado-cafeeirofinalizaram-a-seta-feira-em-campo-positivo.html. Acesso em março de 2014.
} 
Tabela 3

Perfis dos Gestores da Yaguara Ecológico.

\begin{tabular}{|c|c|c|c|}
\hline Gestor & Idade & Formação Profissional & Experiência Anterior \\
\hline $\mathbf{I}$ & 73 & Mestre em administração pública & Executivo da Odebrecht - área de novos negócios \\
\hline II & 71 & Bacharel em Belas Artes & Design de interiores da Pottery Barn e Willians Sonoma \\
\hline III & 48 & $\begin{array}{l}\text { Bachelor of Arts/Liberal, com ênfase em } \\
\text { negócios internacionais. }\end{array}$ & Executiva da Colorado Trading - empresa de agronegócios \\
\hline IV & 36 & $\mathrm{~N} / \mathrm{A}$ & $\mathrm{N} / \mathrm{A}$ \\
\hline $\mathbf{v}$ & 37 & Bacharel em Letras & $\mathrm{N} / \mathrm{A}$ \\
\hline VI & 39 & Bacharel em filosofia e direito & $\begin{array}{l}\text { Chefe de Operações e Conselheiro Geral na Intelligentsia } \\
\text { Coffee\&Tea }\end{array}$ \\
\hline
\end{tabular}

Fonte: Elaborado pelos autores.

\subsection{0 café Yaguara no mercado nacional}

Com as vendas para o Japão consolidadas, a operação nos Estados Unidos descontinuada e vários grãos de tamanho de 14, 15 e 16 prontos para o comércio, a família Peebles decide investir no mercado nacional.

Um dos gestores comenta que a comercialização com os japoneses contribuiu positivamente com a imagem do café Yaguara no Brasil:

Todo mundo sabe que os japoneses são muito rigorosos. Antes de exportar, eles solicitam amostras para certificar se o produto é orgânico. Eles visitam e olham o local de produção. Aí, quando você fala que exporta para o Japão, o café é considerado especial dentro do Brasil (Informante II).

A rede de relacionamentos da Yaguara no circuito gourmet brasileiro foi semeada através da iniciativa de um dos empreendedores, que realiza pessoalmente as entregas nos restaurantes e cafeterias na cidade de Recife. O mesmo cultiva amizade com alguns chefs renomados como, por exemplo, André Saburó Matsumoto, indicado como chef do ano 2013 pela revista Prazeres da Mesa, dono do restaurante Quina do Futuro e do café Tokyo's. O resultado desse trabalho é a presença do café Yaguara em Recife (PE), Maceió (AL), João Pessoa (PB), Curitiba (PR) e São Paulo (SP).

\section{Discussão e Análise do Caso}

\subsection{O Caso e a Teoria de Empreendedorismo Internacional}

De acordo com o relato dos gestores, desde o início das atividades da fazenda Várzea da Onça o mercado internacional foi uma alternativa necessária uma vez que não havia demanda no mercado brasileiro para cafés especiais. Isso coincide com a definição de McDougall, 1989 (p.388) sobre empreendedorismo internacional que afirma ser o "desenvolvimento de novos empreendimentos internacionais ou star-ups que, desde sua origem, comprometem-se com a internacionalização".

Em relação ao modelo desenvolvido por Oviatt e McDougall, 1994 que define os quatro elementos necessários para formação de INV, no caso estudado foi possível verificar a existência dos quatro elementos essenciais. O elemento referente à internalização das atividades pode ser observado nas atividades agrícolas e de processamento do café, entretanto, o objetivo da internalização não foi a redução de custos mas o controle da produção tendo em vista garantir cafés com boa qualidade. A internalização das atividades foi um processo dinâmico que evoluiu junto à parceira Ueshima Coffee Company e resultou numa estrutura hibrida

\section{Tabela 4}

Linha do Tempo do Processo de internacionalização da Yaguara Ecológico.

\begin{tabular}{ll}
\hline Ano & \multicolumn{1}{c}{ Evento } \\
\hline $\mathbf{1 9 7 8}$ & Compra da fazenda várzea da onça em Taquaritinga do Norte (PE). \\
$\mathbf{2 0 0 0}$ & Tatiana P. E James M. Visitam a feira da SCAA nos EUA e conhecem os japoneses do grupo \\
$\mathbf{2 0 0 1}$ & Ueshima Coffee Company (UCC) \\
$\mathbf{2 0 0 1}$ & Representante da UCC visita a fazenda em Taquaritinga do Norte junto com David Peebles \\
$\mathbf{2 0 0 1}$ & Exportam para os EUA e começam a torrar o café no país e vender no comércio local sob o nome de "café sombra". \\
$\mathbf{2 0 0 4}$ & Fazenda adquire primeira máquina para beneficiamento do café \\
$\mathbf{2 0 0 6}$ & Primeiro ano de exportação para o Japão \\
$\mathbf{2 0 0 7}$ & Tatiana Peebles estabelece residência em Taquaritinga do Norte (PE) \\
$\mathbf{2 0 0 9}$ & Cessa exportação do café para os EUA. \\
\hline
\end{tabular}

Fonte: Elaborado pelos autores 
de governança ( $2^{\circ}$ elemento do modelo): a UCC compra o café verde in natura da fazenda, torra no Japão e venda sob o rótulo de Café Pernambuco.

Eles querem baú fechado que é muito caro. O baú tem que ser limpo, mas não podemos utilizar nada que afete o cheiro do café. As estopas de juta tem que ser virgens. (Informante III)

Os elementos referentes à sustentabilidade do negócio e a existência de recursos únicos revelam-se na proposta que a empresa tem em seguir os princípios da agricultura orgânica. Essa prática não é comum no setor cafeeiro brasileiro, em especial na região nordeste do país. De acordo com o SEBRAE (2011), nacionalmente, a produção de cafés especiais se concentra na região Sudeste do Brasil, especificamente nos estados de Minas Gerais e no Espírito Santo.

O desenvolvimento dessas atividades fornece vantagem à empresa que, além de comercializar no exterior com preços superiores, está conquistando o mercado nacional devido a essas características.

"Todo mundo sabe que os japoneses são muito rigorosos. Antes de exportar, eles solicitam amostras para certificar se o produto é orgânico. Eles visitam e olham o local de produção. Aí, quando você fala que exporta para o Japão, o café é considerado especial dentro do Brasil".

O elemento referente à vantagem de localização é um desdobramento da estrutura hibrida no caso analisado. A medida que a empresa comercializa com a Ueshima Coffee Company existe a transmissão e a absorção de conhecimento.

A gente também aprendia com eles (japoneses), porque era um aprendizado, de duas vias, tanto a gente dava, ensinava, como a gente aprendia com eles. (Informante IV)

De acordo com Mello (2009) e Keupp e Gaussman (2009), a figura do empreendedor é relevante para entender a complexidade do fenômeno da internacionalização das empresas. Portanto, o modelo criado por Andersson (2000) pode contribuir para a avaliação do caso Yaguara Ecológico. Andersson (2000), ao criar o modelo, divide o ambiente em três dimensões: ambiente da firma, ambiente meso e ambiente macro.

No nível da firma, a mudança de Tatiana Peebles para Taquaritinga do Norte (PE) alterou a rota de comercialização do café verde in natura que era exportado do Brasil para ser torrado e revendido nos Estados Unidos. Sua vinda para o nordeste mudou a estratégia de comercialização da empresa. A opção de comercializar no mercado nacional foi motivadora e a decisão foi tomada pelos empreendedores.

No nível meso, os gestores da Yaguara tem realizado um trabalho junto aos profissionais do circuito de café gourmet (ex. chefs e baristas) no sentido de ampliar o mercado nacional e desenvolver novos conceitos relacionados a cadeia produtiva de cafés especiais (Folha de Pernambuco, 2013). No nível macro, a preservação de um modo de produção sustentável foi uma escolha dos proprietários, e possibilitou a comercialização do café para o Japão (Prazeres da Mesa, 2013). Contudo, não foi possível observar se as atividades da fazenda e a escolha desse modo produtivo tenham influenciado os concorrentes do setor cafeeiro brasileiro.

\subsection{O Caso e a Teoria Effectuation}

A internacionalização do café para o Japão converge com a perspectiva proposta pela teoria Effectuation. Sarasvathy, 2001a destaca que os empreendedores tem, a priori, um conjunto limitado de "meios" que em conjunto com as limitações do ambiente propiciam a geração de possíveis objetivos. Os gestores da fazenda Várzea da Onça tinham um objetivo inicial de comercializar um café peculiar, mas não estabeleceram junto com este objetivo o modo de atuação no mercado internacional. As condições dinâmicas e desfavoráveis do mercado brasileiro impulsionaram os gestores a buscarem uma solução factível para que o empreendimento funcionasse. Foi então, que Tatiana Peebles e James Mclaughlin participaram da feira de café nos Estados Unidos e estabeleceram, de forma não planejada, contato com a Ueshima Coffee Company (UCC) que firmaram parceria ao longo dos anos.

Ao avaliar o ciclo de ação do empreendedor (WILTBANK et al., 2006) é possível inferir que, após aceitar negociar com os japoneses, o compromisso com o parceiro levou a empresa a fazer algumas adaptações para estabelecer a comercialização com o grupo UCC. As exigências do grupo japonês proveram à empresa experiência e conhecimento que, consequentemente, permitiu aos empreendedores melhorar o processo produtivo e investir nas atividades de cultivo e de processamento do café.

Assim, o estabelecimento da relação com os japoneses expandiu o ciclo de recursos da empresa e permitiu alternância na perspectiva dos 
Tabela 5

Síntese do ciclo de ação do empreendedor aplicado ao caso Yaguara.

\begin{tabular}{|c|c|c|c|c|}
\hline \multirow{2}{*}{\multicolumn{2}{|c|}{$\begin{array}{c}\text { Década de } 1990 \\
\text { Contexto adverso Brasil }\end{array}$}} & \multicolumn{3}{|c|}{ Virada do século } \\
\hline & & Parceiros & $\begin{array}{l}\text { Emergiu da } \\
\text { relação }\end{array}$ & $\begin{array}{l}\text { Contexto mais } \\
\text { favorável }\end{array}$ \\
\hline \multirow{3}{*}{$\begin{array}{l}\text { Meios } \\
\text { - Fazenda } \\
\text { - Café diferenciado } \\
\text { - Empreendedores } \\
\text { com experiência }\end{array}$} & $\begin{array}{l}\text { O que posso fazer? } \\
\text { Internacionalizar para iniciar } \\
\text { as operações da empresa } \\
\text { Visitar feiras e buscar } \\
\text { mercado }\end{array}$ & UCC & $\begin{array}{l}\text { Conhecimento. } \\
\text { Endosso da } \\
\text { marca país Japão }\end{array}$ & $\begin{array}{c}\text { Meios } \\
\text { Nova perspectiva } \\
\text { sobre o mercado } \\
\text { nacional }\end{array}$ \\
\hline & \multicolumn{2}{|c|}{ Decisões acerca da internacionalização } & \multicolumn{2}{|c|}{$\begin{array}{l}\text { Comercialização no } \\
\text { mercado Brasileiro }\end{array}$} \\
\hline & $\begin{array}{c}\text { O que posso fazer? } \\
\text { Exportar e comercializar os } \\
\text { grãos remanescentes nos EUA }\end{array}$ & $\begin{array}{l}\text { Gestores } \\
\text { residentes nos } \\
\text { EUA }\end{array}$ & Não teve êxito & $\begin{array}{c}\text { Meios } \\
\text { Opção de vender os } \\
\text { grãos remanescentes } \\
\text { no mercado nacional }\end{array}$ \\
\hline
\end{tabular}

Fonte: Elaborado pelos autores.

empreendedores que passaram a enxergar o mercado nacional como opção para investimento. É possível inferir que o desenvolvimento da marca Yaguara Ecológico e o objetivo de reposicionar o produto no mercado nacional tenha sido uma consequência dessa nova perspectiva, isso significa que, quando os empreendedores ganharam conhecimento e experiência, a noção de "quem sou eu", "o que eu sei" e "quem eu conheço" mudou e, ao mudar essa concepção, muda-se o horizonte de ação e um novo ciclo se iniciou.

A trajetória internacional do café para os Estados Unidos pode ser interpretada como conversão do ciclo de recursos porque os meios permaneceram os mesmos, ou seja, a opção de enviar grãos para torrar nos Estados Unidos aconteceu porque havia grãos de tamanho inferior àquele exigido pelo mercado japonês e porque parte da família residia em Miami, na época. Portanto, não houve influência da parceria com os japoneses para moldar a visão do futuro (WILTBANK et al., 2006).

Em relação à noção de controle, Sarasvathy, 2001a (p.251) coloca que "o tomador de decisão não fica amarrado à previsibilidade do cenário, mas é o agente transformador que proverá as condições necessárias para o contexto the seja favorável". Assim, a verticalização da produção cafeeira da fazenda Várzea da Onça imprime confiabilidade e validade no produto final e, portanto, favorece o posicionamento da empresa no mercado perante os seus consumidores e parceiros. Isso significa dizer que além dos gestores terem maior gerencia sobre os processos e, consequentemente, produzir um café que obedece a determinados padrões, a verticalização valida as práticas do manejo sustentável e da agricultura orgânica e torna o café um produto gourmet. É importante mencionar que, em relação ao mercado nacional, a verticalização da cadeia produtiva é um fator necessário mas não é suficiente para validar a seguridade do café especial. Fundamental para constituir a imagem de um produto com qualidade e que obedece aos princípios do manejo sustentável advêm da relação com os japoneses dado que existem significados culturalmente constituídos sobre o preciosismo dos nipônicos.

Em relação aos três princípios referentes à lógica particular de controle (SARASVATHY, 2003), no caso Yaguara Ecológico só é possível confirmar o princípio de parceiros ao invés de competidores. A empresa buscou construir uma rede de relacionamentos no mercado exterior e doméstico. Em relação ao princípio de perdas aceitáveis ao invés de retornos esperados, o mesmo pode ser inferido a partir do episódio da tentativa de exploração do mercado norte-americano. De acordo com a narrativa dos entrevistados, é razoável supor que os empreendedores estavam dispostos a aprender com uma operação própria naquele mercado, dispostos, portanto, a enfrentar os custos desse aprendizado. Já com relação ao princípio de alavancar contingências, não há nenhuma evidência de sua ocorrência no caso do empreendimento Yaguara.

Em relação às redes de relacionamentos, com a UCC, a parceria acontece desde 2001, quando o representante da firma japonesa visitou a fazenda com o propósito de conhecer o processo produtivo da fazenda. Desde então, um grupo de estagiários da 
UCC visita a Várzea da Onça, periodicamente, para acompanhar esse processo produtivo e aprender sobre as operações relativas ao café. Em contrapartida a empresa aprende com a UCC sobre as especificidades do processo de comercialização com o Japão e adquire conhecimento referente aos critérios de qualidade que o café deve ter para competir naquele mercado.

$\mathrm{Na}$ arena nacional, as parcerias com os profissionais da área gastronômica possibilitam a troca de conhecimentos referentes ao café torrado, e a marca Yaguara Ecológico paulatinamente está sendo inserida no circuito gourmet.

\section{Considerações Finais}

O objetivo desse estudo foi investigar o papel do empreendedor e as características do processo de internacionalização de uma pequena empresa brasileira produtora de café. Para atender tais objetivos foi escolhida a empresa Yaguara Ecológico e foi realizada uma revisão da literatura sobre os temas de Empreendedorismo Internacional e Effectuation.

A empresa Yaguara Ecológico é um caso brasileiro distinto dentro do mercado de comercialização de cafés especiais. O contexto brasileiro desfavorável durante a década de 1990 impulsionou os gestores a buscar um mercado que estivesse aberto ao consumo de um café diferenciado. A visita à feira nos EUA favoreceu o encontro não planejado da Yaguara com os japoneses da UCC que resultou numa relação simbiótica. O compartilhamento de conhecimento e o processo de aprendizagem de ambas as partes possibilitou a produção de um café diferenciado que carrega uma história contada nos mercados japonês e brasileiro. Esta história foi tecida por duas mãos: a Yaguara e a UCC.

No mercado japonês, o café da Várzea da Onça é vendido em leilões como uma iguaria. Os japoneses narram a experiência que tiveram ao visitar a fazenda e descrevem as particularidades do manejo sustentável. No Brasil, o café é fruto dos conhecimentos adquiridos pelos gestores da Yaguara na sua relação com a UCC e, apesar de ser um produto genuinamente brasileiro, está impregnado de significados culturalmente constituídos relacionados ao Japão.

Permeado a esta trama estão as teorias de Empreendedorismo Internacional e Effectuation. As teorias eleitas para este estudo contribuíram no entendimento do início do processo de internacionalização de uma pequena empresa brasileira do setor de agronegócios, assim como as consequências para a empresa das escolhas feitas pelos empreendedores no percurso de atuação no mercado exterior.

É possível inferir que a empresa se configura como uma INV (OVIATT; MCDOUGALL, 1991) e que o empreendedor tem o poder de alterar as circunstâncias onde a lógica decisória dos empreendedores, desta empresa em particular, adere à perspectiva effectual (SARASVATHY, 2001a). Nesse sentido, este estudo visa contribuir para a teoria de negócios internacionais ao estudar um caso particular de uma pequena empresa de agronegócios onde é possível observar que a parceria foi um elemento chave na constituição do negócio e da sua trajetória internacional.

Esse estudo, de natureza exploratória e qualitativa, não pretende ser conclusivo em relação às pesquisas sobre internacionalização de pequenas empresas brasileiras, sequer daquelas que atuam no setor cafeeiro. A título de sugestão, entende-se que seja recomendável investigar pequenas empresas produtoras de café orgânico no Brasil e buscar semelhanças e diferenças entre aquelas que internacionalizaram ou produzem somente para o mercado nacional.

Por fim, sugere-se um estudo quantitativo junto a pequenas empresas produtoras de café orgânico, localizadas em diferentes regiões do Brasil, onde se buscariam descrever semelhanças e diferenças nas redes de relacionamentos destas e, em especial, se há participação de órgãos governamentais no apoio e incentivo efetivos para a internacionalização das mesmas.

\section{Referências}

- ANDERSSON, S. The Internationalization of the Firm from an Entrepreneurial Perspective. International Studies of Management \& Organization, v. 30, n. 1, p. 6392, 2000.

- International entrepreneurship, born globals and the theory of Effectuation. Journal of Small Business and Enterprise Development, v. 18, n. 3, p. 627-643, 2011. DOI: $10.1108 / 14626001111155745$

- AUtio, E. Creative tension: the significance of Ben Oviatt's and Patricia McDougall's article "Toward a International New Ventures." Journal of International 
Business Studies, v. 36, n. 1, p. 9-19, 2005. DOI: 10.1057/palgrave.jibs.8400117

- BARNEY, J. B. Firm resources and sustained competitive advantage. Journal of Management, v. 17, n. 1, p. 99120, 1991. DOI: 10.1177/014920639101700108

- BIRKINSHAW, J.; BRANNEN, M. Y.; TUNG, R. L. From a distance and generalizable to up close and grounded: reclaiming a place for qualitative methods in international business research. Journal of International Business Studies, v. 42, special issue, p. 573-581, 2011. DOI:10.1057/jibs.2011.19

- CAsillas, J. C. AND ACEDO, F. J. Speed in the Internationalization Process of the Firm. International Journal of Management Reviews, v. 15, n. 1, p. 15-29, 2013.DOI: $10.1111 /$ j.1468-2370.2012.00331.x

- COVIELLO, N.E.; GHAURI, P.N.; MARTIN, K. International competitiveness: empirical findings from SME service firms. Journal of International Marketing, v. 6, n. 2, p. 827, 1998.

- COVIELLO, N. E.; JONES, M. V. Methodological issues in international entrepreneurship research. Journal of Business Venturing, v. 19, n. 4, p. 485-508, 2004. DOI: doi:10.1016/j.jbusvent.2003.06.001

- DEW. N; READ, S.; SARASVAThy, S. Wiltbank, R. Effectual versus predictive logics in entrepreneurial decision-making: Differences between experts and novices. Journal of business venturing, v.24, n. 4, p. 287 309, 2009. DOI:10.1016/j.jbusvent.2008.02.002

- DIB, L. A. R. O. O processo de internacionalização de pequenas e médias empresas e o fenômeno BORN GLOBAL: estudo do setor de software no Brasil. 2008. 352 f. Tese (Doutorado em administração de empresas). COPPEAD - Universidade Federal do Rio de Janeiro UFRJ. Rio de Janeiro. 2008.

- DOLAN, A.; AYLAND, C. Analysis on trial. International Journal of Market Research, v. 43, n. 4, p. 377-389, 2001.

- EISENHARDT, K.M. Building theories from case study research. The Academy of Management Review, v. 14, n. 4, p. 532-550, 1989.

- GALKINA, T.; CHETTY, S. Effectuation and the revisited Uppsala model: networking of internationalizing SMEs. 15th McGill International Entrepreneurship Conference, Anais...Pavia, Italy (pp. 1-21), 2011.

- GALKINA, T. CHETTY, S. Effectuation and Networking of Internationalizing SMEs. In Proceedings of the 54th Annual Meeting of the Academy of International Business Anais Washington, DC, 2012

- GHAURI P. Designing and conducting case studies in international business research. In PIEKARI, R.M. WELCH, C. (Org.) Handbook of Qualitative Research Methods in International Business. London. Edward Elgar. 2004. p.111- 122.

- GIBBERT, M.; RUIGROK, W.; WICKI, B. What passes as a rigorous case study? Strategic Management Journal, $\mathrm{v}$. 29, n. 13, p. 1465-1474, 2008. DOI: 10.1002/smj.722
- gonZaleZ-PEREZ, M. A.; GutierReZ-ViAnA, S. Cooperation in coffee markets: the case of Vietnam and Colombia, Journal of Agribusiness in Developing and Emerging Economies, v. 2, n. 1, p. 57 - 73. 2012. DOI: 10.1108/20440831211219237

- hilal, A. hemais, C. A. O Processo de Internacionalização na Ótica da Escola Nórdica: Evidências Empíricas em Empresas Brasileiras. RAC Revista de Administração Contemporânea, v. 7, n. 1, p. 109-124, 2003. DOI: http://dx.doi.org/10.1590/S141565552003000100006

- JOHANSON J, VAHLNE JE. Internationalization process of firm - model of knowledge development and increasing foreign market commitments. Journal of International Business Studies, v. 8, n. 1, p. 23-32. 1977. DOI: 10.1057/palgrave.jibs. 8490676

- JOHANSON, J.; WIEDERSHEIM-PAUL, F. The Internationalization of the Firm - Four Swedish Cases 1. Journal of Management Studies, v. 12, n. 3, p. 305-323, 1975. DOI: 10.1111/j.1467-6486.1975.tb00514.x

- JONES, M.V.; COVIELLO, N.; TANG, Y.K. International Entrepreneurship research (1989-2009): a domain ontology and thematic analysis. Journal of Business Venturing, v. 26, n. 6, p-632-659, 2011. DOI:10.1016/j.jbusvent.2011.04.001

- KEUPP, M. M.; GASSMANN, O. The Past and the Future of International Entrepreneurship: A Review and Suggestions for Developing the Field. Journal of Management, v. 35, n. 3, p. 600-633, 2009. DOI: $10.1177 / 0149206308330558$

- $\quad$ KISS, A. N.; DANIS, W. M.; CAVUSGIL, S. T. International entrepreneurship research in emerging economies: $A$ critical review and research agenda. Journal of Business Venturing, v. 27, n. 2, p. 266-290, 2012. DOI: 10.1016/j.jbusvent.2011.09.004

- LEÃO, E. A. A Produção de Cafés Especiais no Brasil e a Emergência de Novos Padrões de Competitividade. 2010. 77 f. Dissertação (Ciências Econômicas) Universidade Federal do Paraná - UFPR, Curitiba, 2010.

- martignago, G.; Alperstedt, G. D. A Pesquisa em Gestão Internacional no Brasil entre 2001 e 2010: Um Estudo a Partir dos Anais do Enanpad. In ENANPAD, 2011, Anais Rio de Janeiro: ANPAD, 2011.

- MADSEN, T. K.; SERVAIS, P. The internationalization of Born Globals: An evolutionary process? International Business Review, v. 6, n. 6, p. 561-583, 1997. DOl: 10.1016/S0969-5931(97)00032-2

- MCDougall, P. P. International versus Domestic Entrepreneurship: New Venture Strategic Behavior and Industry Structure. Journal of Business Venturing, v. 4, n. 6, p.387-399, 1989. DOI:10.1016/0883-9026(89)900098

- MCDOUGALL, P.; SHANE, S.; OVIATT, B. M. Explaining the formation of international new ventures: The limits of theories from international business research. Journal of Business Venturing, v. 9, n. 6, p. 469-487, 1994. DOI: 10.1016/0883-9026(94)90017-5 
- MCDOugall, P; OVIATT, B.M.; SHRADER, R. C. Comparison of International and Domestic New Venture. Journal of International Entrepreneurship, v. 1, n. 1, p. 59-82, 2003. DOI 10.1023/A1023246622972

- MELLO, R. D. C. O processo de internacionalização de empresas brasileiras de software: reconciliando diferentes correntes teóricas. 2009. Tese (Doutorado em Engenharia de Produção). COPPE - Universidade Federal do Rio de Janeiro - UFRJ, Rio de Janeiro. 2009.

- MTIgWE, B. Theoretical milestones in international business: The journey to international entrepreneurship theory. Journal of International Entrepreneurship, v. 4, n. 1, p. 5-25, 2006. DOI: 10.1007/s10843-006-5872-5

- OVIATT, B. M.; MCDOUGALL, P. P. Toward a theory of international new ventures. Journal of International Business Studies, v. 25, n. 1, p. 45-64, 1994. DOI: 10.1057/palgrave.jibs. 8400128

- _. Defining International Entrepreneurship and Modeling the Speed of Internationalization. Baylor University, v. 29, n. 5, p. 537-554, 2005. DOl: 10.1111/j.1540-6520.2005.00097.x

- Pelogio, E.A.; ROCHA, L.C.S.;MACHADO, H.V.; ANEZ,M.E.M. Empreendedorismo E Estratégia Sob A Ótica Da Lógica Effectuation. Revista Ibero-Americana de Estratégia - RIAE, v. 12, n. 2, p. 228-249, 2013. DOI: 10.5585/riae.v12i2.1942

- PeRren, L; RAM, M. Case-study method in small business and entrepreneurial research. Mapping boundaries and perspectives. International Small Business Journal, v. 22 n. 1, p. 83-101. 2004. DOI: 10.1177/0266242604039482

- PERRY, J.P.; ChANDleR, G. N.; MARKOVA, G. Entrepreneurial Effectuation: A Review and Suggestions for Future Research. Entrepreneurship Theory and Practice, v. 36, n. 4, p. 837-861. 2012. DOI: 10.1111/j.1540-6520.2010.00435.x

- READ, S.; SARASVATHY, S. Knowing What to Do and Doing What You Know Effectuation as a Form of Entrepreneurial Expertise. The Journal of Private Equity, v. 9, n. 1, p. 45-62, 2005. DOI:10.3905/jpe.2005.605370.

- RIALP, A.; RIALP, J.; KNIGHT, G. A. The phenomenon of early internationalizing firms: what do we know after a decade (1993-2003) of scientific inquiry? International Business Review, v. 14, n. 2, p. 147-166, 2005. DOI: 10.1016/j.ibusrev.2004.04.006

- ROCHA, A. Porque as empresas brasileiras não se internacionalizam? In: Rocha, Angela da (Org). As novas fronteiras: a multinacionalização das empresas brasileiras. Rio de Janeiro. Mauad. p. 13-28, 2003.

- RONDANI, B.; ANDREASSI, T.; BERNARDES, R. C. Microfoundations for Open Innovation: is Effectuation a valid approach for open innovation managers? Revista Gestão e Conexões, v. 2, n. 1, p. 94115, 2013. DOI: http://dx.doi.org/10.13071/regec.23175087.2013.2.1.4968.94-115.

- SARASVATHY, S. Causation and Effectuation: Towards a theoretical shift from economic inevitability to entrepreneurial contingency. Academy of Management Review. v. 26, p. 243-288. 2001a.

Effectual reasoning in entrepreneurial decision making: Existence and bounds. Best paper proceedings, Academy of Management. Washington, p. 3-8, 2001b.

.Entrepreneurship as a science of the artificial. Journal of Economic Psychology, v. 24, n. 2, p. 203-220, 2003. DOI: 10.1016/S0167-4870(02)00203-9

- _. The questions we ask and the questions we care about: reformulating some problems in entrepreneurship research. Journal of Business Venturing, v. 19, n. 5, p. 707-717, 2004. DOI: 10.1016/j.jbusvent.2003.09.006

- SCHUMPETER, J.A. The theory of economic development. Cambridge, MA: Harvard University Press, 1934

- $\quad$ SIMÕES, V. C.; DOMINGUINHOS, P. M. Portuguese Born Globals: An Exploratory Study Alliances and Confrontations: Globalization and the Logics of Trading Blocs. 27 th $E$ EIBA Conference. ESCP-EAP- Paris, France. Anais... 2001.

- VARIS, J.; KUIVALAINEN, O.; SAARENKETO, S. Partner Selection for International Marketing and Distribution in Corporate New Ventures. Journal of International Entrepreneurship, v. 3, n. 1, p. 19-36, 2005. DOI: 10.1007/s10843-005-0270-y

- Venkataraman, S. SARAsvathy, S. Strategy and Entrepreneurship: Outlines of an untold story. In M.A. Hitt, E. Freeman e SJ. Harrison. Handbook of Strategic Management. Oxford. UK. Blackwell. pp. 650-668, 2001.

- Zahra, S.A. \& George, G. International entrepreneurship: The current status of the field and future research agenda. In M.A. Hitt, R.D. Ireland, S.M. Camp, \& D.L. Sexton (Orgs). Strategic entrepreneurship: Creating a new mindset (pp. 255-288). Oxford, UK: Blackwell Publishers.

- WILTBANK, R.; DEW, N.; READ, S.; SARASVATHY, S. What to Do Next? The Case for Non-Predictive Strategy. Strategic Management Journal, v. 27, n. 10, p. 981-998, 2006. DOI: $10.1002 / \mathrm{smj} .555$

- YIN, R. K. (Org.) Estudo de Caso. Planejamento e Métodos. Porto Alegre. 3 Ed. Bookman, 2005.

\section{Referências relativas ao setor pesquisado.}

- Consórcio Pesquisa Café (INFORME CAFÉ). Informe Estatístico do Café 2013. Quadro de exportação do agronegócio total. Ranking por valores 2013. Disponível em http://www.consorciopesquisacafe.com.br/index.php/i mprensa/noticias/420-aprespdfviiispcb. Acesso em junho de 2013.

- Empresa Brasileira de Pesquisa Agropecuária (EMBRAPA). Cultivo de Café Orgânico. 2006. Disponível em:

http://sistemasdeproducao.cnptia.embrapa.br/FontesH 
TML/Cafe/CafeOrganico_2ed/mercado.htm. Acesso em junho de 2013

- Folha de Pernambuco. Caderno Sabores. Edição dezembro de 2013.

- Fundação Procafé (PROCAFÉ, 2013). Artigo com especificidades do grão Conillon. Disponivel em http://www.fundacaoprocafe.com.br/sites/default/files /publicacoes/pdf/folhas/Folha011Robusta.pdf. Acesso em junho de 2013.

- Organização Internacional do Café (OIC). Relatório mensal com informação sobre o Café (Agosto de 2012).
Disponível em: http://dev.ico.org/documents/cmr0812-e.pdf Acesso em junho de 2013.

- Revista Prazeres da Mesa. Desbravadores do Agreste. Edição 113. Março, 2013.

- Serviço de Apoio a Micro e Pequenas Empresas (SEBRAE). Boletim Setorial do Agronegócio Café. Disponível em: http://www.sebrae.com.br/setor/cafe/osetor/mercado/Boletim\%20Setorial\%20Cafeicultura.pdf . Acesso em junho de 2013.

\title{
Sobre os Autores
}

- Paula Porto é Doutoranda em Administração pela Pontifícia Universidade Católica do Rio de Janeiro PUC/RJ, Rio de Janeiro, RJ, Brasil.E-mail: paulappontes@gmail.com

- Renato Cotta de Mello é Professor adjunto do Instituto Coppead de Administração - Universidade Federal do Rio de Janeiro - UFRJ/RJ, Rio de Janeiro, RJ, Brasil. E-mail: renato@coppead.ufrj.br

\section{International entrepreneurship and Effectuation: the Yaguara Ecológico Coffee case}

\author{
Paula Porto ${ }^{A}$ and Renato Cotta de Mello ${ }^{B}$ \\ ${ }^{A}$ Pontifícia Universidade Católica do Rio de Janeiro - PUC/RJ, Rio de Janeiro, RJ, Brazil. \\ ${ }^{B}$ Universidade Federal do Rio de Janeiro - UFRJ/RJ, Rio de Janeiro, RJ, Brazil.
}

\section{ARTICLE DETAILS}

Article history:

Received 09 December de 2014

Accepted 01 July 2015

Available online in 19 December 2015

Double Blind Review System

\section{Scientific Editor}

Felipe Mendes Borini

\section{Keywords:}

International entrepreneurship

Effectuation

Coffee

Brazil

\begin{abstract}
The purpose of this study is to investigate the role of the entrepreneur and the characteristics of the internationalization process for Yaguara Ecológico, a small Brazilian coffee producer, in the light of different theoretical approaches. A literature review was done with special attention given to the theories of International Entrepreneurship and Effectuation. This paper deals with the International New Venture phenomenon (OVIATT; McDOUGALL, 1994), and in order to understand the importance of entrepreneurs in a company's internationalization process, the Effectuation theory was chosen that offers alternatives to describe how they think and behave when starting a new venture (PERRY et al., 2012). The research method used a single case study and in-depth interviews were conducted with company managers. The results suggest that the theories offer explanations for the company's internationalization activities; however, some characteristics of this trend did not adhere to the theoretical propositions.
\end{abstract}

(C) 2015 Internext | ESPM. All rights reserved! 